\title{
Muscle activation patterns during backward walking in people with chronic ankle instability
}

Tharani Balasukumaran, Uri Gottlieb and Shmuel Springer * (D)

\begin{abstract}
Background: Altered walking patterns are often described in individuals with chronic ankle instability (CAI). Contemporary treatment paradigms recommend backward walking (BW) to improve locomotion in people with musculoskeletal disorders. The purpose of this study was to determine whether muscle activity and activation variability during BW differs between subjects with and without CAI.
\end{abstract}

Methods: Sixteen participants with CAI and 16 healthy controls walked on a treadmill at their self-selected speed under BW and forward walking (FW) conditions. Surface electromyography (EMG) data for the peroneus longus, tibialis anterior, medial gastrocnemius and gluteus medius muscles were collected. EMG amplitude normalized to maximum voluntary isometric contraction (\%MVIC) and the standard deviation (SD) of the \%MVIC EMG amplitude was calculated throughout the gait cycle. In addition, the area under the curve (AUC) of the \%MVIC EMG amplitude was calculated before and after initial contact (pre-IC: $90-100 \%$ of stride; post-IC: 0-10\% of stride).

Results: No differences between groups were noted in the \%MVIC amplitude or activation variability (SD of \%MVIC EMG) under BW or FW. In both groups, decreased tibialis anterior $(p<0.001)$ and gluteus medius $(p=0.01)$, and increased medial gastrocnemius $(p<0.001)$ activation were observed during pre- and post-IC under BW condition.

Conclusion: Participants with CAI and healthy controls have similar muscle activity patterns during BW. Yet, the results should be interpreted with caution due to the heterogeneity of the CAI population.

Keywords: Chronic ankle instability, Walking, Electromyography

\section{Background}

Ankle sprains are among the most common musculoskeletal injuries [1, 2]. Up to $59 \%$ of individuals with previous history of an ankle sprain develop chronic ankle instability (CAI) [3]. CAI is a function diminishing condition characterized by repetitive episodes or perception of the ankle giving way. It may be accompanied by ongoing symptoms such as pain, weakness, and reduced ankle range of motion $[4,5]$. When compared with healthy participants, individuals with CAI display deficits

\footnotetext{
* Correspondence: shmuels@ariel.ac.il

Faculty of Health Sciences, Department of Physical Therapy, Ariel University, Ariel, Israel
}

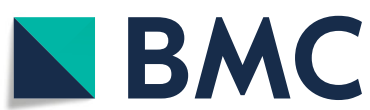

(c) The Author(s). 2020 Open Access This article is licensed under a Creative Commons Attribution 4.0 International License which permits use, sharing, adaptation, distribution and reproduction in any medium or format, as long as you give appropriate credit to the original author(s) and the source, provide a link to the Creative Commons licence, and indicate if changes were made. The images or other third party material in this article are included in the article's Creative Commons licence, unless indicated otherwise in a credit line to the material. If material is not included in the article's Creative Commons licence and your intended use is not permitted by statutory regulation or exceeds the permitted use, you will need to obtain permission directly from the copyright holder. To view a copy of this licence, visit http://creativecommons.org/licenses/by/4.0/ The Creative Commons Public Domain Dedication waiver (http://creativecommons.org/publicdomain/zero/1.0/) applies to the data made available in this article, unless otherwise stated in a credit line to the data.

in sensorimotor control, such as impaired sense of joint position [6], muscle weakness due to arthrogenic muscles inhibition [7] and decreased postural control [8].

The precise analysis of electromyography (EMG) muscle activity during movement is an essential step in understanding sensorimotor control. Studies that assessed amplitude of muscle activity during walking reported differences between individuals with and without CAI. While walking, participants with CAI were reported to have increased peroneus longus activity before and after initial contact (IC) [9-11], lower tibialis anterior and greater medial gastrocnemius muscle activation before IC [11], and increased gluteus medius muscle activation amplitude 
during late stance through early swing phase [11]. However, other studies did not find differences in the amplitude of muscle activation between the CAI and control groups $[12,13]$.

Another factor that seems to be affected by CAI is the variability of muscle function during walking. Up to date, two main techniques were used for assessing variability of muscle function during walking in subjects with CAI. Kautzky et al. [14] utilize traditional linear variability measures such as, the standard deviation (SD) of timing of muscle activation relative to IC (quantified in milliseconds), the SD of percent of muscle activation time across the stride cycle, and the coefficient of variation (COV) of activation amplitude before and after IC. Individuals with CAI had more variable time of activation of the biceps femoris relative to IC, as well as, increased variability of gluteus medius EMG maximal amplitude prior to IC compared to a healthy group. Koldenhoven and colleagues [15] provided more informative and dynamic presentation of muscle variability by plotting the SD of the EMG amplitude across the entire gait cycle and used it as the primary outcome to present variability. Compared to healthy controls, CAI group had decreased variability in muscle activation amplitude of the peroneus longus from 1 to $10 \%, 32-38 \%$ and $56-$ $100 \%$ of the gait cycle, as well as reduced tibialis anterior variability from 33 to $42 \%, 57-69 \%$, and $95-99 \%$ of the gait cycle. Altered EMG amplitude variability may indicate a constraint in the adaptability of the sensorimotor system. Furthermore, it has been shown that challenging walking conditions, such as walking at fast speeds, emphasize differences in muscle activity patterns between healthy individuals and those with CAI [13].

Contemporary treatment paradigms for altered gait in people with CAI recommend gait training [16]. Backward walking (BW) is a gait activity with additional complexity compared to regular forward walking (FW), that may be novel and challenging task even for healthy individuals. Evidence suggests that BW utilizes additional elements, presumably supraspinal, in addition to a common spinal drive of gait [17, 18]. Kurz et al. [19] reported increase in sensorimotor cortical activation measured by functional near infrared spectroscopy in healthy adults during BW. It has also been reported that exercise of BW in untrained healthy adults caused neural adaptations [19]. As BW requires more central nervous system resources than does FW, it may serve as a training method to enhance sensorimotor control of movement among individuals with CAI.

BW has indeed been shown to improve control of movement in patients with neurological lesions and with musculoskeletal disorders. A recent study reported the effectiveness of BW as a rehabilitation technique for improving knee proprioception in patients after anterior cruciate ligament reconstruction [20]. The beneficial effects of BW have also been demonstrated in people with patellofemoral pain syndrome [21], and in with low back pain [22].

Studies that assessed muscle firing patterns in BW compared to FW indicated that it is not a simple reversal of the EMG pattern of FW [23, 24]. The EMG activity of the rectus femoris and vastus medialis were considerably higher when walking backward rather than forward [25, 26]. Significant differences were also found in the activation of the ankle muscles. Both ankle flexors and extensors are coactivated at early stance during FW, compared to activation of the ankle flexors only during BW [27]. Moreover, it was found that the mean EMG activity of the gluteus medius and tibialis anterior throughout the gait cycle is higher in BW than in FW [27].

The current study investigated the effects of forward and backward walking conditions on EMG amplitude and variability of the peroneus longus, tibialis anterior, medial gastrocnemius and gluteus medius muscles among subjects with and without CAI. We hypothesized that during $\mathrm{BW}$, compared to healthy controls, individuals with CAI would have increased amplitude and activation variability of peroneus longus and tibialis anterior muscles, as measured by EMG.

\section{Methods}

The study was approved by the University Institutional Review Board approved the study, approval number: AU-HEA-20190213. All participants provided written informed consent.

\section{Participants}

The study sample included 16 participants with CAI and 16 aged-matched healthy controls. The inclusion criteria for the CAI group were in accordance with The International Ankle Consortium recommendations [4, 28]: (i) history of at least one significant ankle sprain that occurred at least 12 months prior to the study, characterized by inflammatory symptoms and caused at least 1 day of decreased physical activity, (ii) history of at least two episodes of 'giving way' and feelings of ankle joint instability during the last 6 months, (iii) the most recent acute ankle sprain occurred more than 3 months prior to study enrollment, (iv) a positive response to at least five yes/no questions (question 1, plus four others) of the Ankle Instability Instrument $[5,28]$.

The control group included healthy participants with no history of ankle sprain. Exclusion criteria from both groups were history of ankle fracture, other pathological conditions or surgical procedures in the lower extremity within 1 year of study participation or had vestibular or neurological disorders. 


\section{Procedure}

The study was conducted during one visit at the Neuromuscular and Human Performance Laboratory, at Ariel University. EMG activity of the peroneus longus, tibialis anterior, medial gastrocnemius and gluteus medius muscles was evaluated under both FW and BW walking conditions, while participants walked barefoot on a treadmill. Participants were instructed to walk at a comfortable, self-selected pace. Before data collection, they were provided with an opportunity to habituate to forward and backward walking on the treadmill. At this time, walking speed was adjusted according to the participant's comfort. This self-selected, comfortable speed during forward and backward walking was used during the gait assessments. EMG data were collected using a wireless EMG system (Delsys Trigno, Delsys Inc., Boston, MA) at $2000 \mathrm{~Hz}$. Before data collection, participants' skin was shaved and cleaned with isopropyl alcohol to minimize impedance. Electrode placement was performed according to Surface Electromyography for the NonInvasive Assessment of Muscles (SENIAM) guidelines [29]. Lightweight $(<15 \mathrm{~g})$ wireless rectangular sensors (37x26x15mm) with parallel-bar silver contact electrodes were placed over the muscle belly of the recorded muscle using a double-sided adhesive interface (Delsys Inc., Boston, MA). The Delsys EMG senor's range is $11 \mathrm{mV}$, its resolution is $168 \mathrm{nV} / \mathrm{bit}$, and the overall channel noise is $<0.75 \mathrm{uV}$. Before walking, EMG activity during maximal voluntary isometric contraction (MVIC) was measured against manual resistance for all recorded muscles. Visual inspection was made prior to data collection to minimize crosstalk. It should be also noted that Delsys sensors are designed with an interface and inter-electrode distance to offer the optimal crosstalk suppression while maintaining the EMG signal amplitude. Each MVIC was performed three times for $5 \mathrm{~s}$, with $60 \mathrm{~s}$ rest between contractions.

The raw EMG signal was filtered through band pass filter between 50 and $500 \mathrm{~Hz}$ with the use of a fourthorder Butterworth filter, and processed with EMG works software (version 4.1.1, Delsys, Boston, MA). MVIC EMG signals were subjected to a root mean square (RMS) algorithm to convert all amplitude measures to positive values. Gait events were identified using inertial measurement sensors that were placed near the participant's heel during FW and near the second metatarsal head during BW. Gait cycles were isolated by identifying consecutive heel or toes strikes. The vertical accelerometer signal from the sensor placed near the heel (for FW) or second metatarsal head (for BW) was used to identify initial contact. A foot contact was characterized as a rapid change in vertical acceleration signal followed by a rather lengthy steady-state period [30]. Subjects walked barefoot on a motorized treadmill (VO2 Challenger, Taiwan). The condition order was fixed, with FW being recorded first, following by BW walking. Fifteen consecutive strides from the beginning of each walking condition were analyzed.

The EMG amplitudes during the gait cycle were transformed to 100 data points for each of the 15 consecutive strides, and their output was displayed as a percentage of the MVIC EMG value (\%MVIC), which can be used to establish a common ground when comparing data between participants. In addition, to assess stride-to-stride variability of muscle activity, the standard deviation (SD) of the EMG amplitude (as \%MVIC) was calculated for each participant at each of the 100 data points. The \%MVIC served as the dependent variable for comparing EMG amplitude across the entire gait cycle between groups, whereas the SD of \%MVIC served as the dependent variables for comparing activation variability across the entire gait cycle between groups. Finally, the area under the curve (AUC) of the muscles' activation (\%MVIC) was calculated before and after IC (pre-IC; post-IC) during both walking conditions. Pre-IC was defined as $90-100 \%$ of the gait cycle, and post-IC was defined as $0-10 \%$ of the gait cycle.

These periods during the gait cycle have previously been demonstrated to be relevant to the study of gait dynamics in people with CAI $[14,15]$. The AUC during PreIC and Post-IC served as the dependent variable for comparing the adaptation of each group from FW to BW.

\section{Statistical analysis}

Descriptive statistics included mean $(\mathrm{M})$ and standard deviations (SD). Simple chi-square and independent ttests were used to compare baseline characteristics between the CAI and control groups.

For between-groups analysis, under each walking condition, group mean muscle amplitude activity (\%MVIC) and EMG variability (presented as SD) with their respective 95\% confidence interval (CI) were plotted for each muscle throughout the gait cycle [31, 32]. A significant, meaningful difference was defined in case a nonoverlapping CI was found for consecutive $3 \%$ of the stride $[15,33]$. According to this method, post-hoc analysis was conducted only when significant betweengroups differences in muscle mean amplitude activation or SD was found.

To compare the adaptation of each group to BW, a linear mixed model with group and condition as fixed effects and participants as random effect was conducted to examine the effect of group and condition on the AUC during Pre -and Post-IC of each muscle separately. In addition, EMG amplitude difference between FW and BW was calculated (FW - BW) for each muscle and plotted with the respective 95\% CI. As previously described, non-overlapping CIs for more than $3 \%$ of the gait cycle was considered as significant difference in 
Table 1 Participant characteristics

\begin{tabular}{llll}
\hline Parameter & CAl & Control & $p$-value \\
\hline Age (years) & $25.44(2.39)$ & $25.56(3.44)$ & 0.57 \\
Height $(\mathrm{m})$ & $1.71(0.11)$ & $1.72(0.10)$ & $68.36(12.44)$ \\
Weight $(\mathrm{kg})$ & $71.69(13.82)$ & $9 \mathrm{~F} / 7 \mathrm{M}$ & 0.40 \\
Sex $(\mathrm{F} / \mathrm{M})$ & $8 \mathrm{~F} / 8 \mathrm{M}$ & $1.12(0.10)$ & $0.63(0.15)$ \\
Forward walking speed (m/sec) & $1.05(0.16)$ & - & 0.14 \\
Backward walking speed (m/sec) & $0.62(0.14)$ & - & - \\
Ankle with recurrent sprains (RT/LT) & $14 / 2$ & - & - \\
Time since last sprain (weeks) & $20.5(18.18)$ & - & - \\
Ankle Instability Instrument score & $6(1.15)$ & &
\end{tabular}

CAI Chronic ankle instability, $R T$ Right, $L T$ Left

adaptation. A significance level of $<0.05$ was set. Analysis was conducted using IBM SPSS Statistics for Windows, Version 24.0 (IBM Corp, Armonk, NY).

\section{Results}

\section{Participant characteristics}

Participant characteristics are presented in Table 1. There were no differences in baseline characteristics (age, height, weight and sex) between groups.

\section{EMG amplitude activity across the cycle}

Figure 1 presents the mean EMG activity as \%MVIC throughout the gait cycle for each of the tested muscles. As depicted in the figures, overlaps in CIs between the CAI and healthy control groups were consistent throughout the gait cycle in all tested muscles in both walking conditions. Therefore, no significant differences between groups in mean EMG activity can be concluded under BW or FW.

\section{EMG amplitude variability across the gait cycle}

Figure 2 shows the mean SD of EMG amplitude throughout the gait cycle for each of the tested muscles. As depicted in the figure, overlaps between the CAI and healthy control groups were consistent throughout the gait cycle in all tested muscles in both walking conditions. Therefore, no significant differences between groups in EMG amplitude variability can be concluded under BW or FW conditions.

\section{Adaptation to BW}

Figure 3 shows the pre-IC and post-IC AUC values of all muscles. The results of the linear mixed model analysis for AUC are presented in Table 2. No significant differences between groups were found. Compared to FW, before and after IC under BW condition, decreased tibialis anterior and gluteus medius activation were evident in both groups. In contrast, medial gastrocnemius activation was significantly higher during BW compared to FW in these periods of the gait cycle in both groups. However, no between condition differences were found for peroneus longus activation at pre-IC or at post-IC.

The differences in EMG amplitudes between FW and $\mathrm{BW}$ are presented in Fig. 4. As depicted in the figure, overlaps between the CAI and healthy control groups were consistent throughout the gait cycle in all tested muscles.

\section{Discussion}

The purpose of this study was to determine whether leg muscle EMG amplitude and activation variability during BW differs between groups with and without CAI. Major differences were found between BW and FW. However, in contrast to our hypothesis, no between group differences were evident. This may indicate that participants with CAI and healthy controls use similar motor adaptations to BW.

To the best of our knowledge, no previous study has fully assessed EMG patterns during BW in people with CAI. Therefore, comparison is only possible with earlier reports that evaluated EMG during FW in this population. In a study that assessed EMG amplitude of the peroneus longus, tibialis anterior, lateral gastrocnemius, rectus femoris, biceps femoris, and gluteus medius muscles, no differences were noted between CAI and healthy groups at either $100 \mathrm{msec}$ before or $200 \mathrm{msec}$ after IC, during shod, treadmill walking at fixed $4.8 \mathrm{~km} / \mathrm{h}$ speed. In this study, the area under the RMS curve was normalized to quiet standing [12]. Similarly, a recently published study used equivalent methods to analyze EMG amplitudes of peroneus longus, tibialis anterior, medial gastrocnemius, and gluteus medius muscles during shod, treadmill FW at self-selected or $120 \%$ of self-selected speed. The authors reported no group differences between people with CAI and individuals who had an ankle sprain but learned to cope and returned to pre- 

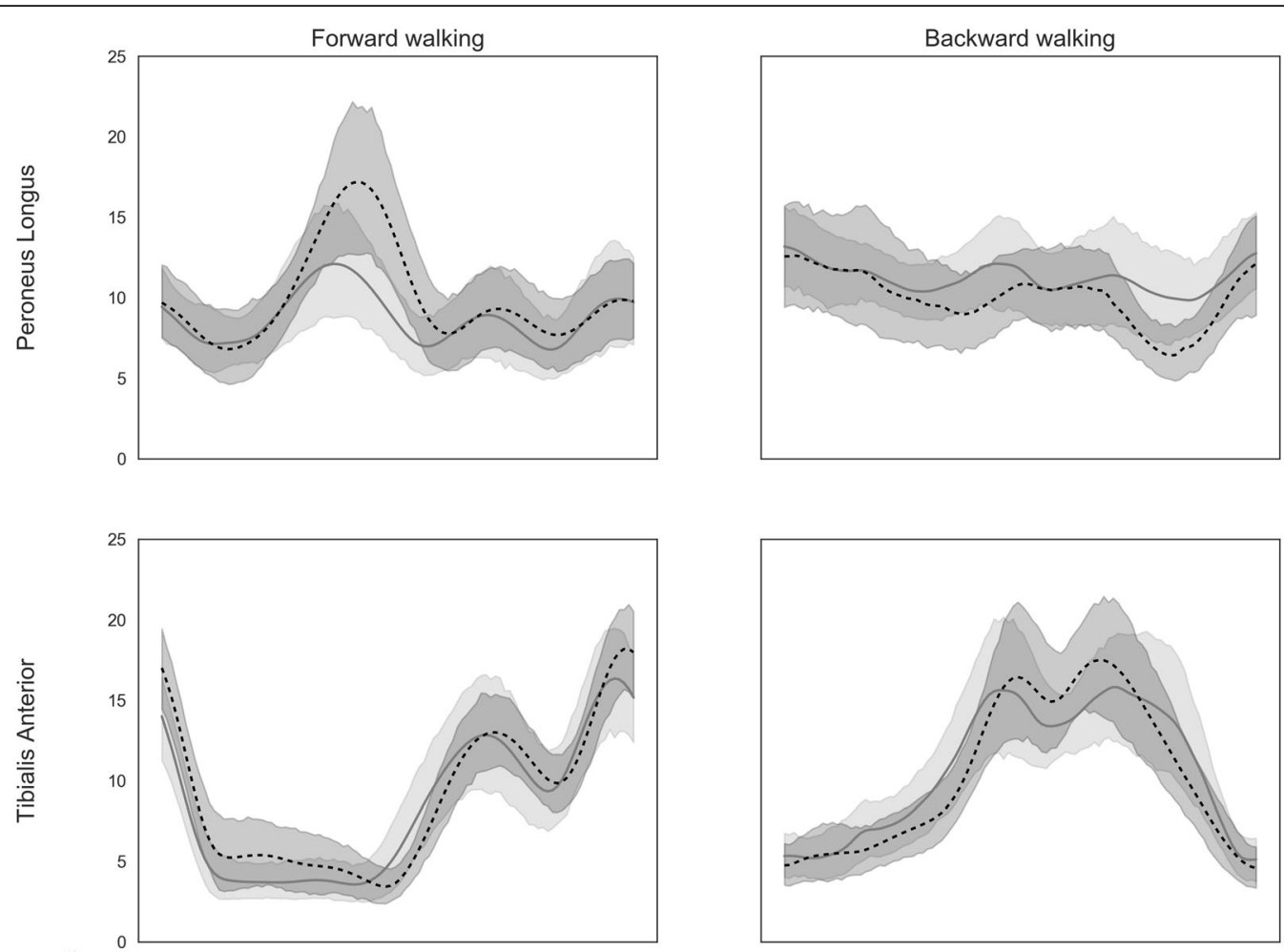

$\sum_{\substack{0 \\ \infty}}^{0}$
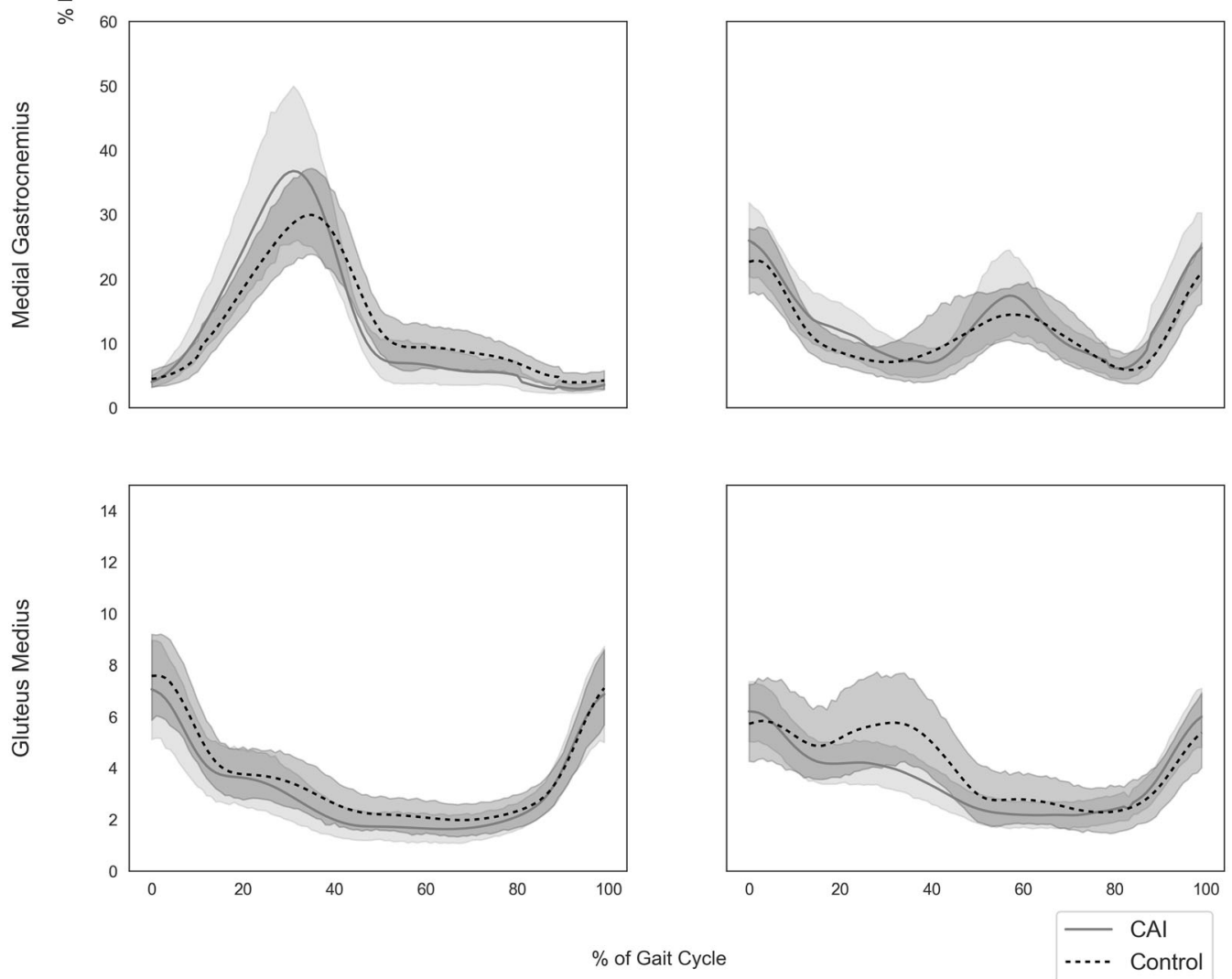

Fig. 1 Muscle mean activation as \% of maximum voluntary isometric contraction (\%MVIC) across the gait cycle. Shaded areas represent 95\% confidence intervals 

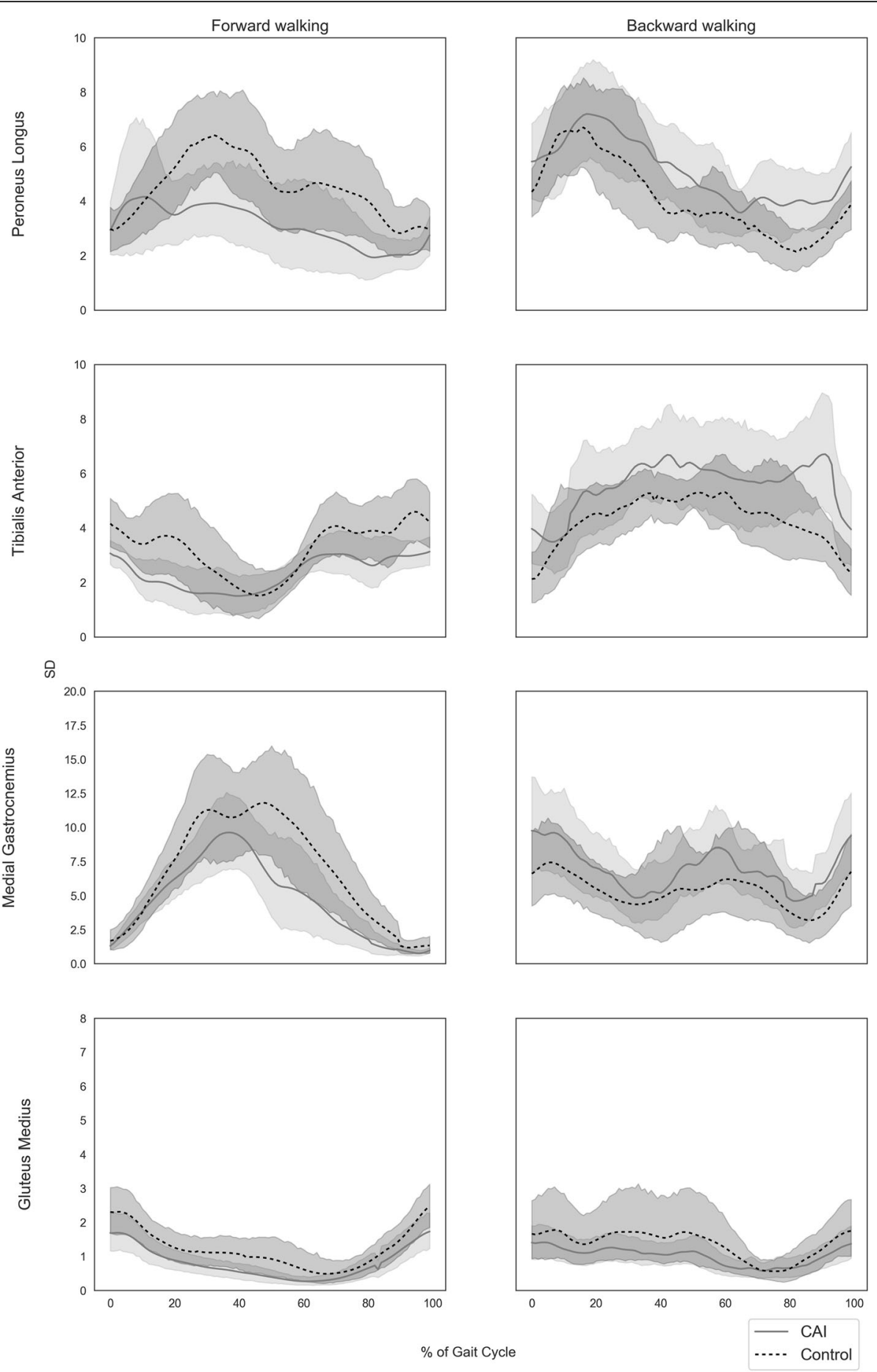

Fig. 2 Standard deviations of muscle activity across the gait cycle. Shaded areas represent $95 \%$ confidence intervals

injury levels of function [34]. Likewise, several studies that evaluated EMG amplitude of leg muscles during dynamic tasks such as jump landings also reported no differences between participants with CAI and matched healthy controls [35-37]. For example, a recently published study by Simpson and colleagues [37] recorded muscle activity from the peroneus longus and peroneus brevis, tibialis anterior, and medial gastrocnemius, during pre- to post unexpected and expected single leg drop-landings. No differences in average EMG amplitude were found between individuals with CAI and healthy controls. 

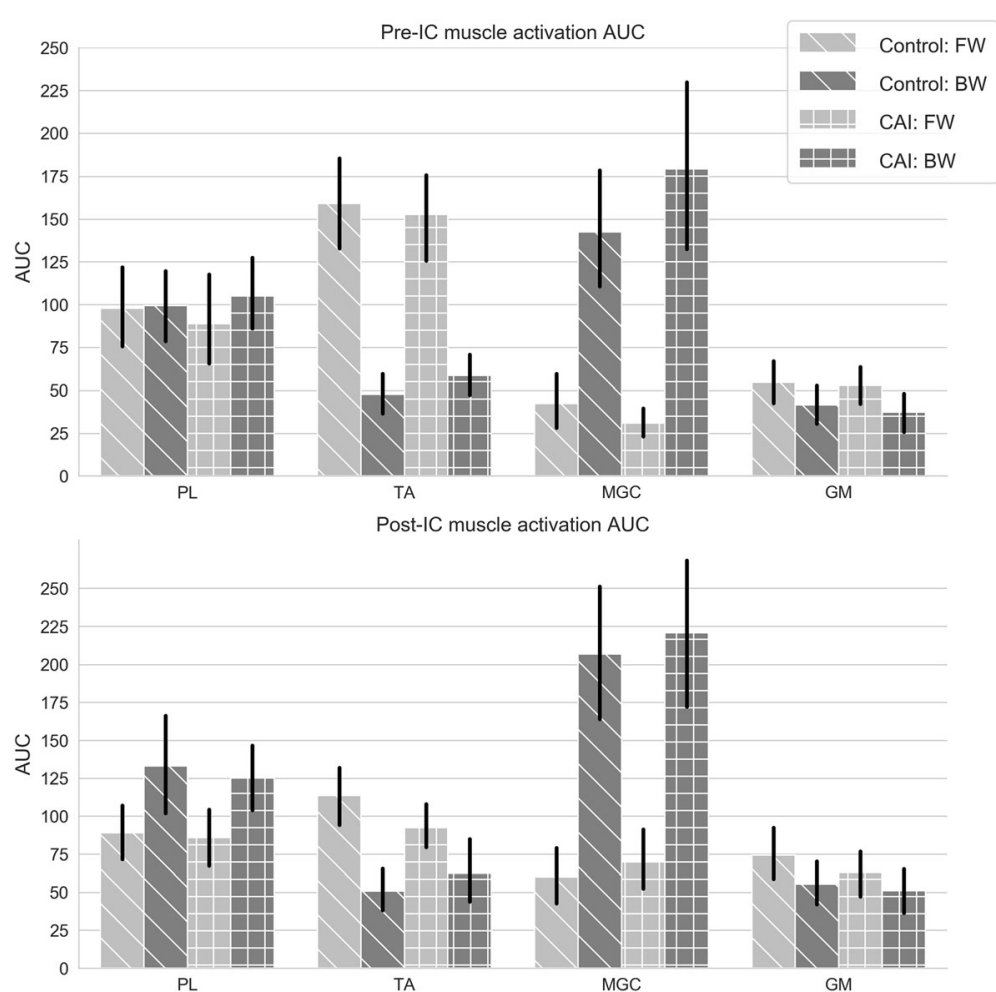

Fig. 3 Area under the curve (AUC) for muscle activation as \%MVIC at pre-IC and post-IC

Consisted with the reports that evaluated EMG amplitude and found no differences between subjects with and without CAI, some evidence suggests no difference in muscle activation variability between these populations. Kautzky et al. [14] studied the variability in muscle function during FW using several methods as mentioned above. There were no significant differences between CAI and healthy controls groups in the variability of activation of the peroneus longus, tibialis anterior, lateral gastrocnemius, rectus femoris, biceps femoris, and gluteus medius across the stride cycle. Therefore, the present findings and the above-mentioned studies may provide evidence that similar motor control strategies are used by individuals with and without CAI.

Yet, conflicting results were reported in other studies. Louwerens et al. [13] evaluated CAI and healthy subjects during shod, treadmill walking at self-selected speed and at $50 \%$ of self-selected speed. EMG linear envelope transformed signals were normalized to the to the highest recorded peak during the gait cycle. Subjects with CAI displayed significant increase in tibialis anterior amplitude during the stance phase under both walking conditions. Delahunt et al. [9] observed increased area under the RMS curve of peroneus longus activity 40-80 msec after IC during barefoot, treadmill FW at $4 \mathrm{~km} / \mathrm{h}$ speed in participants with CAI, with normal activity of this muscle pre-IC. Koldenhoven et al. [11] reported that during shod, treadmill $\mathrm{FW}$ at $4.8 \mathrm{~km} / \mathrm{h}$, participants with CAI had decreased tibialis anterior activity and significantly increased peroneus longus, medial gastrocnemius, and gluteus medius activity pre-IC, with no difference post-IC. In another study by this group, decreased stride-to-stride variability in both the tibialis anterior and peroneus longus activation was identified post-IC in individuals with CAI [15].

Due to the large discrepancies between studies, it seems that no sound conclusion can be drawn regarding leg muscle EMG amplitude and activation variability during gait and dynamic tasks among individuals with CAI. However, several explanations are proposed for the inconsistencies observed between studies. Some discrepancies might be due to the heterogeneity of the CAI population. The updated paradigm of CAI suggests that there is a list of impairments that people with CAI as a group, are likely to demonstrate; however, each individual may present certain clinical and performance outcomes that are affected by personal and environmental factors [38]. Specifically, all the CAI participants in the current study met established standards for the diagnosis [5]. However, according to the Ankle Instability Instrument, only 3 of 16 participants reported that they felt unstable while walking on a flat surface. Previous studies 
Table 2 Results of the linear mixed model analysis for group, condition and interactions. The control group and forward walking are references for group and condition

\begin{tabular}{|c|c|c|c|c|c|}
\hline & & Pre-IC & & Post-IC & \\
\hline & & Estimate $(95 \% \mathrm{Cl})$ & $p$-value & Estimate $(95 \% \mathrm{Cl})$ & $p$-value \\
\hline $\mathrm{PL}$ & Intercept & $97.8(71.0,124.6)$ & & $89.0(69.5,108.5)$ & \\
\hline & Group & $-8.9(-46.8,29.0)$ & 0.63 & $-3.2(-30.7,24.4)$ & 0.82 \\
\hline & Condition & $1.6(-31.0,34.4)$ & 0.92 & $23.7(-6.4,53.7)$ & 0.12 \\
\hline & Group * Condition & $14.9(-31.3,61.2)$ & 0.52 & $15.6(-26.0,57.1)$ & 0.45 \\
\hline TA & Intercept & $159.1(132.9,185.3)$ & & $113.6(95.4,131.8)$ & \\
\hline & Group & $-6.4(-43.4,30.7)$ & 0.73 & $-20.5(-46.3,5.2)$ & 0.11 \\
\hline & Condition & $-111.3(-135.4,-87.2)$ & $<0.001$ & $-62.8(-84.9,-40.7)$ & $<0.001$ \\
\hline & Group * Condition & $17.2(-16.9,51.3)$ & 0.31 & $22.4(-9.0,53.8)$ & 0.16 \\
\hline MGC & Intercept & $42.3(28.8,55.8)$ & & $60.2(40.2,80.2)$ & \\
\hline & Group & $-11.4(-30.4,7.7)$ & 0.23 & $9.9(-18.4,38.2)$ & 0.48 \\
\hline & Condition & $100.1(63.7,136.6)$ & $<0.001$ & $146.7(105.8,187.5)$ & $<0.001$ \\
\hline & Group * Condition & $36.2(-16.2,88.6)$ & 0.17 & $4.3(-53.5,62.0)$ & 0.88 \\
\hline GM & Intercept & $54.6(42.0,67.2)$ & & $74.5(56.9,92.0)$ & \\
\hline & Group & $-1.9(-19.8,16.0)$ & 0.83 & $-11.6(-36.4,13.1)$ & 0.35 \\
\hline & Condition & $-13.0(-22.9,-3.2$ & 0.01 & $-19.0(-33.6,-4.5)$ & 0.01 \\
\hline & Group * Condition & $-2.3(-16.2,11.6)$ & 0.73 & $7.3(-13.2,27.9)$ & 0.47 \\
\hline
\end{tabular}

* CAI chronic ankle instability, IC initial contact, PL peroneus longus, TA tibialis anterior, MGC medial gastrocnemius, GM gluteus medius

have shown that only very complex walking situations, such as walking with a cognitive dual task, may differentiate individuals with CAI from controls $[39,40]$. Indeed, comparing some previous studies $[9,11,15]$ with the present study, during self-selected FW there were no differences between CAI and matched controls. This may indicate that the individuals with CAI that were investigated, no functional impairments while performing a simple ambulation task. These findings are consisted with previous data showing that walking under selfselected speed may not challenge the sensorimotor control of subjects with CAI [39]. Thus, it is possible that while BW on a treadmill required some level of adaptation from both groups, it was not challenging enough to discriminate their gait performance. Assessments with more challenging tasks, such as BW with dual task and BW at fast speeds may be more appropriate for testing gait impairments in individuals with CAI. As previously suggested [38], it is recommended to identify patientspecific complaints and impairments to guide the development of assessments and interventions in CAI.

Another aspect that could explain the variation in findings between studies is related to data collection. The reference for EMG normalization differs significantly between studies; thus, it is difficult to conclude whether the differences were due to the group or to the normalization methods. Furthermore, while some studies evaluated discrete EMG signals [9, 12], others have analyzed continuous data from the entire gait cycle [34].
In addition, systematic reviews indicated significant differences in muscle activity during barefoot and shod walking and running [41, 42]. In the present study, we evaluated both continuous and discrete (Pre- and PostIC) EMG data, which were collected while participants walked barefoot at a self-selected speed; thus, the results should be interpreted with caution when compared to other studies.

Although BW did not distinguish between groups, it influenced muscle activation in both groups compared to FW. This finding is agreement with previous studies that reported changes in lower limb muscle activation patterns during BW, as compared to FW [18, 20, 23, 27]. Consistent with previous research, the gastrocnemius muscle was mostly active during early stance in BW gait, whereas the tibialis anterior was active during early stance in FW [27]. The greater activation of the gluteus medius muscle observed in the present study during BW may be related to an effort to provide more control during pre- and post- IC. It was shown that during BW, as compared to $\mathrm{FW}$, the pelvis is less stable vertically [43]. This decrease in pelvic stability may be the cause of the increased activity of the gluteus medius muscle.

Interestingly, a systematic review of studies that assessed the effects of CAI on muscle activity during FW concluded that while some studies observed significant differences between the CAI and the control groups, and others did not, it seems that increased activity of the peroneus longus pre-IC is often found in participants 


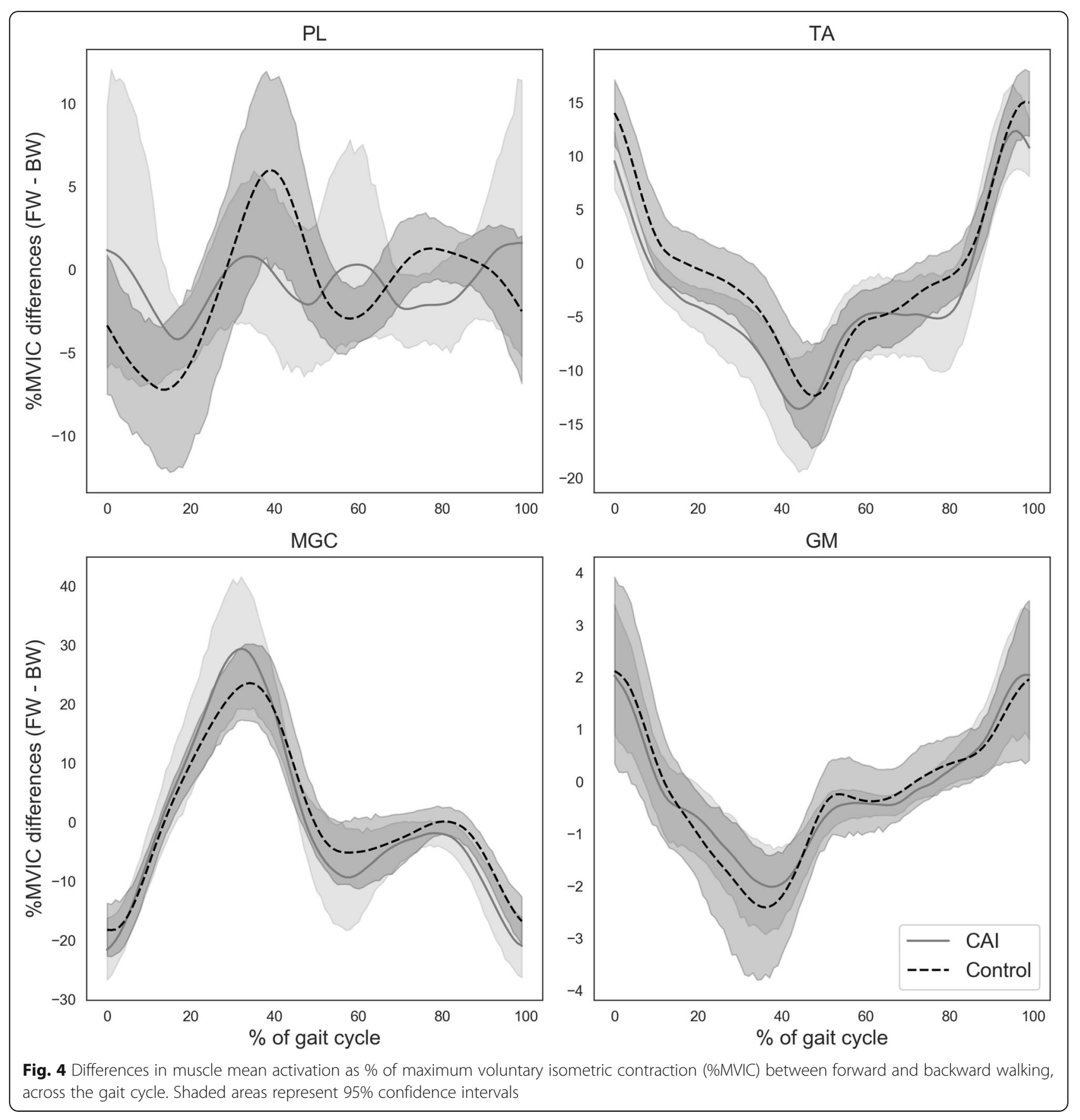

with CAI [44]. However, the present study did not find differences in peroneus longus activation either between groups or between walking conditions. Therefore, based on these results, it is unlikely that BW can be used as specific training to improve control over the peroneus longus in CAI. Yet, current evidence suggests that BW uses additional elements, presumably supraspinal, in addition to a common FW spinal drive [17, 18]. The significant alterations in muscle activity during BW in both groups, may support this notion. Thus, it may be used as a training technique in order to stress the sensorimotor system. There are currently no evidence-based recommendations for CAI gait retraining. Therefore, future research should assess the effect of BW training on individuals with CAI.

There are large discrepancies in EMG parameters between studies that assessed muscle activity during gait in the CAI population. Based on previous research, in the present investigation we examined both EMG amplitude and AUC, which are two of the most commonly used 
outcomes [44]. Furthermore, the time and duration of activation were not analyzed directly. Yet, the overlaps between groups in the amplitude of the tested muscles throughout the gait cycle may suggest that the time and duration of muscle activity do not differ between groups. Finally, to date, only two studies reported variability of muscle function during walking in individuals with CAI $[14,15]$. The variability of EMG amplitude that was also analyzed in the current study may contribute to the understanding of the consistency of motor pattern in CAI population. It is recommended that the methods applied in this study should be used in future investigations that evaluate gait in this population. Such studies should confirm the present results with more participants, including subgroups of people with CAI who have varied levels of impairment.

\section{Conclusions}

Backward gait training is becoming a popular treatment method for people with musculoskeletal disorders. Therefore, it is important to understand how the application of BW affects motor control among individuals with CAI. This study indicates that, compared to FW, participants with CAI and healthy controls demonstrate significant changes in mean EMG activation and activation variability in leg muscles during BW. However, there are no differences between groups. Due to the heterogeneity of the CAI population, the results should be interpreted with caution. Future investigations that evaluate motor control during BW with larger and varied cohorts of people with CAI are warranted.

\section{Abbreviations \\ AUC: Area under the curve; BW: Backward walking; CAl: Chronic ankle instability; Cl: Confidence interval; COV: Coefficient of variation:; \\ EMG: Electromyography; FW: Forward walking; GM: Gluteus medius; IC: Initial contact; LT: Left; M: Mean; MGC: Medial gastrocnemius; MVIC: Maximum voluntary isometric contraction; PL: Peroneus longus; RMS: Root mean square; RT: Right; SD: Standard deviation; TA: Tibialis anterior}

\section{Acknowledgments}

The authors would like to thank the study participants.

\section{Authors' contributions}

TB conceived the study and participated in the design, data collection, statistical analysis and manuscript preparation. UG participated in statistical analysis and manuscript preparation. SS participated in the design of the study, data collection, statistical analysis, and manuscript preparation. All authors read the final version and agree with its submission to the journal.

\section{Funding}

University internal funding.

\section{Availability of data and materials}

The datasets used and analyzed during the current study are available from the corresponding author on reasonable request.

\section{Ethics approval and consent to participate}

The study was approved by Ariel University Institutional Review Board, approval number.
AU-HEA-20190213.Participants were recruited from a public university setting and provided written informed consent prior to participating in the study.

Consent for publication

Not applicable.

\section{Competing interests}

The authors declare no competing interests.

Received: 25 February 2020 Accepted: 15 July 2020

Published online: 25 July 2020

References

1. Fong DT-P, Hong Y, Chan L-K, Yung PS-H, Chan K-M. A systematic review on ankle injury and ankle sprain in sports. Sports Med. 2007;37:73-94.

2. Waterman BR, Owens BD, Davey S, Zacchilli MA, Belmont PJ. The epidemiology of ankle sprains in the United States. J Bone Joint Surg Am. 2010;92:2279-84.

3. Yeung MS, Chan KM, So CH, Yuan WY. An epidemiological survey on ankle sprain. Br J Sports Med. 1994;28:112-6.

4. Delahunt E, Coughlan GF, Caulfield B, Nightingale EJ, Lin C-WC, Hiller CE. Inclusion criteria when investigating insufficiencies in chronic ankle instability. Med Sci Sports Exerc. 2010;42:2106-21.

5. Gribble PA, Delahunt E, Bleakley C, Caulfield B, Docherty CL, Fourchet F, et al. Selection criteria for patients with chronic ankle instability in controlled research: a position statement of the international ankle consortium. J Orthop Sports Phys Ther. 2013:43:585-91.

6. Yokoyama S, Matsusaka N, Gamada K, Ozaki M, Shindo H. Position-specific deficit of joint position sense in ankles with chronic functional instability. J Sports Sci Med. 2008;7:480-5 https://www.ncbi.nlm.nih.gov/pmc/articles/ PMC3761917/. Accessed 14 Jun 2020.

7. McVey ED, Palmieri RM, Docherty CL, Zinder SM, Ingersoll CD. Arthrogenic muscle inhibition in the leg muscles of subjects exhibiting functional ankle instability. Foot Ankle Int. 2005;26:1055-61.

8. Hertel J. Sensorimotor deficits with ankle sprains and chronic ankle instability. Clin Sports Med. 2008;27:353-70 vii.

9. Delahunt E, Monaghan K, Caulfield B. Altered neuromuscular control and ankle joint kinematics during walking in subjects with functional instability of the ankle joint. Am J Sports Med. 2006;34:1970-6.

10. Ty Hopkins J, Coglianese M, Glasgow P, Reese S, Seeley MK. Alterations in evertor/invertor muscle activation and center of pressure trajectory in participants with functional ankle instability. J Electromyogr Kinesiol. 2012; 22:280-5. https://doi.org/10.1016/j.jelekin.2011.11.012.

11. Koldenhoven RM, Feger MA, Fraser JJ, Saliba S, Hertel J. Surface electromyography and plantar pressure during walking in young adults with chronic ankle instability. Knee Surg Sports Traumatol Arthrosc. 2016;24: 1060-70.

12. Feger MA, Donovan L, Hart JM, Hertel J. Lower extremity muscle activation in patients with or without chronic ankle instability during walking. J Athl Train. 2015;50:350-7.

13. Louwerens JW, van Linge B, de Klerk LW, Mulder PG, Snijders CJ. Peroneus longus and tibialis anterior muscle activity in the stance phase. A quantified electromyographic study of 10 controls and 25 patients with chronic ankle instability. Acta Orthop Scand. 1995;66:517-23.

14. Kautzky K, Feger MA, Hart JM, Hertel J. Surface electromyography variability measures during walking: effects of chronic ankle instability and prophylactic bracing. Athletic Training Sports Health Care. 2015;7:14-22. https://doi.org/10.3928/19425864-20150121-04.

15. Koldenhoven RM, Feger MA, Fraser JJ, Hertel J. Variability in center of pressure position and muscle activation during walking with chronic ankle instability. J Electromyogr Kinesiol. 2018;38:155-61.

16. Donovan $L$, Hertel J. A new paradigm for rehabilitation of patients with chronic ankle instability. Phys Sportsmed. 2012;40:41-51.

17. Hoogkamer W, Meyns P, Duysens J. Steps forward in understanding backward gait: from basic circuits to rehabilitation. Exerc Sport Sci Rev. 2014; 42:23-9.

18. Jansen K, De Groote F, Massaad F, Meyns P, Duysens J, Jonkers I. Similar muscles contribute to horizontal and vertical acceleration of center of mass in forward and backward walking: implications for neural control. J Neurophysiol. 2012;107:3385-96. 
19. Kurz MJ, Wilson TW, Arpin DJ. Stride-time variability and sensorimotor cortical activation during walking. Neuroimage. 2012;59:1602-7.

20. Shen $M$, Che S, Ye D, Li Y, Lin F, Zhang Y. Effects of backward walking on knee proprioception after ACL reconstruction. Physiother Theory Pract. 2019. https://doi.org/10.1080/09593985.2019.1681040.

21. Flynn TW, Soutas-Little RW. Patellofemoral joint compressive forces in forward and backward running. J Orthop Sports Phys Ther. 1995;21:277-82.

22. Dufek J, House A, Mangus B, Melcher G, Mercer J. Backward walking: a possible active exercise for low back pain reduction and enhanced function in athletes. Journal of Exercise Physiology Online. 2011;14:17-27 https://go. gale.com/ps/i.do? $p=A O N E \& s w=w \& i s s n=10979751 \& v=2.1 \& i t=r \& i d=G A L E \%$ 7CA361184670\&sid=googleScholar\&linkaccess=abs. Accessed 14 Jun 2020.

23. Thorstensson A. How is the normal locomotor program modified to produce backward walking? Exp Brain Res. 1986;61:664-8.

24. Winter DA, Pluck N, Yang JF. Backward walking: a simple reversal of forward walking? J Mot Behav. 1989;21:291-305.

25. Chen LY, Su F, Chiang PY. Kinematic and EMG analysis of backward walking on treadmill. In: Annual International Conference of the IEEE Engineering in Medicine and Biology - Proceedings. Institute of Electrical and Electronics Engineers Inc. In; 2000. p. 825-7. https://researchoutput.ncku.edu.tw/en/ publications/kinematic-and-emg-analysis-of-backward-walking-on-treadmill. Accessed 14 Jun 2020.

26. Flynn TW, Soutas-Little RW. Mechanical power and muscle action during forward and backward running. J Orthop Sports Phys Ther. 1993;17:108-12.

27. Grasso R, Bianchi L, Lacquaniti F. Motor patterns for human gait: backward versus forward locomotion. J Neurophysiol. 1998;80:1868-85.

28. Gribble PA, Delahunt E, Bleakley CM, Caulfield B, Docherty CL, Fong DT-P, et al. Selection criteria for patients with chronic ankle instability in controlled research: a position statement of the international ankle consortium. J Athl Train. 2014;49:121-7. https://doi.org/10.4085/1062-6050-49.1.14.

29. Hermens HJ, Freriks B, Merletti R, Stegeman DF, Blok JH, Rau G, et al. European recommendations for surface electromyography: results of the SENIAM project. 1999.

30. Nwanna O. Validation of an Accelerometry based method of human gait analysis. ETD Archive 2014. https://engagedscholarship.csuohio.edu/ etdarchive/764.

31. Hopkins WG, Marshall SW, Batterham AM, Hanin J. Progressive statistics for studies in sports medicine and exercise science. Med Sci Sports Exerc. 2009; 41:3-13.

32. Masson MEJ, Loftus GR. Using confidence intervals for graphically based data interpretation. Can J Exp Psychol/Revue canadienne de psychologie expérimentale. 2003;57:203-20. https://doi.org/10.1037/h0087426.

33. Chinn L, Dicharry J, Hertel J. Ankle kinematics of individuals with chronic ankle instability while walking and jogging on a treadmill in shoes. Phys Ther Sport. 2013;14:232-9.

34. Koldenhoven RM, Hart J, Saliba S, Abel MF, Hertel J. Gait kinematics \& kinetics at three walking speeds in individuals with chronic ankle instability and ankle sprain copers. Gait Posture. 2019;74:169-75.

35. Brown C, Ross S, Mynark R, Guskiewicz K. Assessing functional ankle instability with joint position sense, time to stabilization, and electromyography. J Sport Rehabil. 2004;13:122-34. https://doi.org/10.1123/ jsr.13.2.122.

36. Levin O, Vanwanseele B, Thijsen JRJ, Helsen WF, Staes FF, Duysens J. Proactive and reactive neuromuscular control in subjects with chronic ankle instability: evidence from a pilot study on landing. Gait Posture. 2015:41:106-11.

37. Simpson JD, Stewart EM, Turner AJ, Macias DM, Wilson SJ, Chander H, et al. Neuromuscular control in individuals with chronic ankle instability: a comparison of unexpected and expected ankle inversion perturbations during a single leg drop-landing. Hum Mov Sci. 2019;64:133-41.

38. Hertel J, Corbett RO. An updated model of chronic ankle instability. J Athl Train. 2019:54:572-88.

39. Springer S, Gottlieb U. Effects of dual-task and walking speed on gait variability in people with chronic ankle instability: a cross-sectional study. BMC Musculoskelet Disord. 2017;18:316. https://doi.org/10.1186/s12891-017-1675-1.

40. Tavakoli S, Forghany S, Nester C. The effect of dual tasking on foot kinematics in people with functional ankle instability. Gait Posture. 2016;49: 364-70.

41. Franklin S, Grey MJ, Heneghan N, Bowen L, Li F-X. Barefoot vs common footwear: a systematic review of the kinematic, kinetic and muscle activity differences during walking. Gait Posture. 2015;42:230-9.
42. Thompson MA, Lee SS, Seegmiller J, McGowan CP. Kinematic and kinetic comparison of barefoot and shod running in mid/forefoot and rearfoot strike runners. Gait Posture. 2015;41:957-9.

43. Wu Y, Xiao F, Gu D-Y. Local dynamic stability of the trunk segments and lower extremity joints during backward walking. Conf Proc IEEE Eng Med Biol Soc. 2015;2015:5303-6.

44. Moisan G, Descarreaux M, Cantin V. Effects of chronic ankle instability on kinetics, kinematics and muscle activity during walking and running: a systematic review. Gait Posture. 2017;52:381-99.

\section{Publisher's Note}

Springer Nature remains neutral with regard to jurisdictional claims in published maps and institutional affiliations.
Ready to submit your research? Choose BMC and benefit from:

- fast, convenient online submission

- thorough peer review by experienced researchers in your field

- rapid publication on acceptance

- support for research data, including large and complex data types

- gold Open Access which fosters wider collaboration and increased citations

- maximum visibility for your research: over $100 \mathrm{M}$ website views per year

At $\mathrm{BMC}$, research is always in progress.

Learn more biomedcentral.com/submissions 